International Journal of

Environmental Research and

Public Health

ISSN 1660-4601

www.mdpi.com/journal/ijerph

Article

\title{
Association Between Waist-to-Height Ratio, Isolated and Combined Morbidities and C-Reactive Protein in the Elderly: A Clinical-Epidemiological Study
}

Jousianny Patrício da Silva ${ }^{1} *$, Raquel Patrícia Ataíde Lima ${ }^{1}$, Danielle de Carvalho Pereira ${ }^{1}$, Cassia Surama de Oliveira Silva ${ }^{1}$, Maria da Conceição Rodrigues Gonçalves ${ }^{2}$, Malaquias Batista Filho ${ }^{3}$, Rosália Gouveia Filizola ${ }^{2}$, Ronei Marcos de Moraes ${ }^{4}$, Luiza Sonia Rios Asciutti ${ }^{5}$ and Maria José de Carvalho Costa ${ }^{2}$

1 Graduate Program in Nutritional Sciences, Center for Health Sciences/NIESN-Interdisciplinary Studies in Health and Nutrition, Federal University of Paraíba, Castelo Branco, João Pessoa, PB 58059-900, Brazil; E-Mails: raquelpatriciaal@ hotmail.com (R.P.A.L); danicarvalhop@hotmail.com (D.C.P.); suramajpa@ hotmail.com (C.S.O.S.)

2 Undergraduate Program in Nutrition, Center for Health Sciences, Federal University of Paraiba, João Pessoa, PB 58059-900, Brazil; E-Mails: raulceica@ig.com.br (M.C.R.G.); rosaliafilizola@gmail.com (R.G.F.); mjc.costa@terra.com.br (M.J.C.C.)

3 Undergraduate Program in Mother and Child Health (IMIP), Institute Mother and Child Professor Fernando Figueira, Board of Research, Boa Vista, Recife, PE 50070-550, Brazil;

E-Mail: malaquias.imip@gmail.com

4 Graduate Program in Decision Models and Health, Department of Statistics, Center of Exact and Natural Sciences, Federal University of Paraíba, João Pessoa, PB 58051-000, Brazil;

E-Mail: ronei@de.ufpb.br

5 Department of Nutrition, Faculty of Medical Sciences, João Pessoa, João Pessoa, PB 58010-000, Brazil; E-Mail: luiza.asciutti@terra.com.br

* Author to whom correspondence should be addressed; E-Mail: jousianny@ hotmail.com; Tel./Fax: +55-83-3216-7417.

Received: 17 June 2014; in revised form: 4 September 2014 / Accepted: 9 September 2014 / Published: 16 September 2014

Abstract: The aim of this study was to analyze the association between waist-to-height ratio (WHtR) and C-reactive protein (CRP) in the elderly (considering their most prevalent morbidities and lifestyles), to investigate the relationship between this anthropometric index and the presence of the most prevalent morbidities (isolated or combined), and to 
identify which morbidities (analyzed individually) would have greater associations with WHtR. This cross-sectional population-based epidemiological study of a stratified sampling comprised 170 elderly individuals between 60 and 90 years of age (both genders). Home visits were used to administer questionnaires and to perform anthropometric measurements and blood collection. The mean patient age was younger than 70 years, with women comprising the majority $(69.41 \%)$ and with $90 \%$ of the patients presenting with inadequate WHtR. Hypertension was the most prevalent morbidity in this cohort $(58.52 \%)$, and when analyzed in combination, hypertension plus obesity were the most frequently diagnosed morbidities $(17.65 \%)$. Obesity, which was among the most prevalent comorbidities, was the only comorbidity combined with WHtR $(p=0.0019)$. Individuals with no morbidities had lower mean WHtR values compared with individuals with at least one morbidity $(p=0.0075)$. In the multiple linear regression model, it was identified that when individuals had one or more of the most prevalent comorbidities, the mean WHtR increased by $0.0415(p=0.0065)$. A correlation between WHtR and CRP ( $p=0.0379)$ was also verified. Based on the relationships observed between WHtR (isolated or in combination, data unpublished) and CRP among the elderly, WHtR may represent a screening tool because it is a simple and effective anthropometric index.

Keywords: waist-to-height ratio; C-reactive protein; morbidities; elderly

\section{Introduction}

As the population ages, increased longevity results in greater numbers of elderly individuals with higher survival rates [1-3]. These circumstances represent an interesting field for the development of modern pathophysiological and epidemiological studies of the different contexts in which the process of epidemiological transition is occurring [4,5], thus highlighting the importance of studying the elderly population. Thus, there is concern about regarding the increased incidence of excessive weight or obesity in the elderly [6] due to the correlation of these morbidities with an increased risk for developing non-communicable chronic diseases (NCDs).

As an independent risk factor, abdominal obesity is directly associated with several morbidities [7], as well as an increased risk for cardiovascular diseases, which is the major cause of mortality among NCDs, also in elderly [8] and leads to a widespread use of resources for evaluating abdominal fat accumulation $[9,10]$. Among the measurements of central obesity, waist-to-height ratio (WHtR) is a particularly excellent tool to discriminate the chances likelihood of obesity related to cardiovascular risks compared with the body mass index (BMI) for both sexes [11]. WHtR is also an excellent tool for discriminating other morbidities, such as diabetes mellitus, atherogenic dyslipidemia and metabolic syndrome, when analyzed individually [12].

Like anthropometric parameters, other variables are able to detect probable health risks, such as the plasma levels of inflammatory markers, particularly C-reactive protein (CRP), which predicts the development of cardiometabolic diseases [13]. The CRP measurement has also emerged as an 
important predictor of the incidence of NCDs, particularly obesity [14,15]. In this case, the measurement of inflammatory markers is directly related to fat percentage, whereas pro inflammatory cytokines secreted by the adipose tissue reinforce the hepatic synthesis of CRP, supporting the idea that CRP might be elevated in obese individuals [16,17]. However, this predictive ability is not consensual consistent. In one study, no associations between the presence of metabolic syndrome and high CRP levels were found [18].

Considering that non-communicable chronic diseases induce elevation in CRP values, and that the prevalence of these diseases is higher in the elderly, as is the elevation of CRP values [19-21], it is appropriate to carry out this study, due to its innovative character, aiming to analyze the association between WHtR and CRP in the elderly, as well as the relationship of this anthropometric index with the presence of the most prevalent morbidities in elderly populations when concomitantly analyzed in isolation and in combination.

\section{Experimental Section}

\subsection{Study Characterization}

This epidemiological study, was developed through Household Population Research, which is linked to the "First Diagnosis and Intervention of Food and Nutritional Status and Most Prevalent Non-communicable Diseases in the Population of João Pessoa, Brazil” (I DISANDNT/JP) project, conducted from July 2008 to January 2010. All subjects gave their informed consent for inclusion before they participated in the study. The study was conducted in accordance with the protocol was approved by the Ethics Committee of Center for Health Sciences (CCS), Federal University of Paraíba (protocol number 0493).

\subsection{Sampling}

A representative sample of the city population was stratified using $\mathrm{R}$ software [22] and information was collected from individuals in all age groups by home visits; however, this study only included the elderly population. Considering the variables analyzed, the total study sample comprised 170 elderly patients between 60 and 90 years of age (both genders), with complete data based on the sampling model adopted. More specific information about the sample definition and data collection are provided in a previously published study developed by the DISANDNT/JP [23] team.

\subsection{Data Collection}

After training the team and after the pilot study, activities related to the study objectives were performed. The anthropometric evaluations included weight, height and waist circumference measurements. Each measurement procedure was performed in triplicate and the mean values were used. These measures were taken in the households of individuals participating. Excessive weight was assessed by BMI using the parameters proposed by the WHO, which considers general obesity as a BMI level $\geq 30 \mathrm{~kg} / \mathrm{m}^{2}$ [24]. Abdominal obesity was assessed using the WHtR ratio for which the recommendation is that the waist value corresponds to half of the height value in centimeters for men and women [25]. 
After the patients fasted, qualified and trained nursing professionals collected blood samples in the patients' homes for hs-CRP analysis. The samples were analyzed at the Clinical Laboratory of the "Lauro Wanderley" University Hospital where quantitative analysis was conducted by the agglutination of latex particles using an hs-CRP kit (BioSystems Reagents and Instruments, Barcelona, Spain). The hs-CRP cut-off points for individuals between 60 and 64 years of age were $<8.5 \mathrm{mg} / \mathrm{dL}$ for females and $<7.9 \mathrm{mg} / \mathrm{dL}$ for males; for individuals 65 to 90 years of age, the cut-off values were $<6.6 \mathrm{mg} / \mathrm{dL}$ for females and $<6.8 \mathrm{mg} / \mathrm{dL}$ for males [26].

The presence of various diseases is common in the elderly [27]. Morbidities were self-reported in the questionnaire, being defined by a "yes" answer to the question: "Have you ever been told to you by a doctor that you have any morbidity? Which one?" [28]. This age group was evaluated, considering the number of individuals without any morbidities, individuals with only one morbidity (i.e., an isolated morbidity), and the number of individuals with one or more morbidities (i.e., combined morbidities).

Notably, demographic and socioeconomic descriptions of the elderly study population, as well as individual lifestyles, including smoking, alcohol consumption, the use of medications and physical activity, were also part of this study. Alcohol consumption was verified using the Quantitative Food Frequency Questionnaire (QFFQ) as reported by Luna et al. [23]. The activity level descriptions followed the recommendations of the American College of Sports Medicine [29], which considers a physically active individual as one who performs at least 150 minutes of physical activity per week.

The number of subjects $(n=260)$ accounted for $12.81 \%$ of the entire population found in selected households $(n=2030)$. The elderly population originally selected $(n=212)$ comprised $18 \%$ of all subjects $(n=1175)$ and after drop-outs $(n=46)$, the study group comprised 170 seniors representing $14 \%$ of the selected population $(n=1175)$, higher than the percentage of the elderly in the municipality, which is $9.12 \%$ according to the Institute of Municipal Development and State of Paraiba [1].

\subsection{Statistical Analysis}

Descriptive statistics were initially applied, represented by simple frequency using central tendency and dispersion measures (i.e., median, mean, standard deviation and range). Due to the non-normality of some variables, non-parametric tests were used. Spearman's correlation test between the WHtR and CRP values was applied to analyze the dependence between these variables. To relate the WHtR and CRP variables with the discrete variables, the Wilcoxon test for the comparison of the means was used. Moreover, to determine whether there was an association between the WHtR and morbidities when analyzed in isolation, Fisher's exact test was used. Finally, to adjust the WHtR and CRP research variables, the following multiple regression models were used:

$\mathrm{WHtR}=\beta 0+\beta 1 \times \mathrm{CRP}+\beta 2 \times$ morbidities $(1$ or more $)+\beta 3 \times$ smoking $+\beta 4 \times$ alcohol $+\beta 5 \times$ physical activity $+\beta 6 \times$ gender $+\beta 7 \times$ age + error, and

$\mathrm{CRP}=\beta 0+\beta 1 \times \mathrm{WHtR}+\beta 2 \times$ morbidities $(1$ or more $)+\beta 3 \times$ smoking $+\beta 4 \times$ alcohol $+\beta 5 \times$ physical activity $+\beta 6 \times$ gender $+\beta 7 \times$ age + error

A significance level of $5 \%$ was adopted for all statistical tests, and the data analysis was performed using R software [17]. 


\section{Results}

The sample consisted of 170 individuals with an average age younger than 70 years; the majority of the individuals were female. The mean WHtR value was $0.60 \mathrm{~cm}$, with the majority of individuals presenting inadequate WHtR (>0.50) (Table 1). Regarding the anthropometric data, similar percentages of underweight, normal weight, overweight and obesity were observed between males and females. Of note, the values for overweight and obesity were considered to be relevant to the study population because, according to the WHO [19], more than $60 \%$ of individuals are overweight. Additionally, with regard to lifestyle, most individuals were sedentary and used medications (Table 1).

Regarding the prevalence of morbidities when analyzed in isolation (i.e., the number of elderly patients with a single morbidity), hypertension was observed to be the most prevalent $(32.35 \%)$, followed by obesity $(8.23 \%$ ) and diabetes (3.53\%) (data not shown). However, when individuals with a single morbidity were analyzed in combination with individuals with combined comorbidities, the percentage of these pathologies (i.e., hypertension, obesity and diabetes) increased to $58.23 \%$, $30 \%$ and $12.35 \%$, respectively. However, when only the combined morbidities were analyzed (i.e., individuals with more than one morbidity), it was observed that the highest prevalence occurred for "hypertension + obesity" (17.65\%), followed by "hypertension + diabetes" and "diabetes + obesity".

Table 1. Characteristics of the study population.

\begin{tabular}{|c|c|c|c|c|c|}
\hline Characteristics & Mean & Median & SD & Range & $\mathbf{N}(\%)$ \\
\hline \multicolumn{6}{|c|}{ Demographic and socioeconomic description } \\
\hline \multicolumn{6}{|c|}{ Gender } \\
\hline Male & & & & & $52(30.59)$ \\
\hline Female & & & & & $118(69.41)$ \\
\hline Age (years) & 68.80 & 67.50 & 7.28 & 30.00 & \\
\hline Family income $(\mathrm{R} \$)$ & 2137.89 & 1200.00 & 2342.84 & $13,938.00$ & \\
\hline \multicolumn{6}{|c|}{ Educational level (years) } \\
\hline 0 years & & & & & $13(7.64)$ \\
\hline Up to 9 years & & & & & $99(58.23)$ \\
\hline More than 9 years & & & & & $55(32.35)$ \\
\hline Not provided & & & & & $3(1.78)$ \\
\hline \multicolumn{6}{|c|}{ Anthropometric characteristics } \\
\hline Weight $(\mathrm{kg})$ & 66.61 & 65.00 & 13.23 & 78.20 & \\
\hline Height (m) & 1.55 & 1.55 & 0.09 & 0.49 & \\
\hline Waist $(\mathrm{cm})$ & 92.92 & 92.50 & 11.61 & 72.30 & \\
\hline BMI $\left(\mathrm{kg} / \mathrm{m}^{2}\right)^{\infty}$ & 27.51 & 26.84 & 4.74 & 27.27 & \\
\hline Normal weight ${ }^{\S}$ & 22.84 & & & & $57(33.52)$ \\
\hline Overweight $^{\S}$ & 27.32 & 27.26 & 1.51 & 4.85 & $61(35.88)$ \\
\hline
\end{tabular}


Table 1. Cont.

\begin{tabular}{|c|c|c|c|c|c|}
\hline Characteristics & Mean & Median & SD & Range & $\mathbf{N}(\%)$ \\
\hline Obesity ${ }^{\S}$ & 33.21 & 32.19 & 3.28 & 13.45 & $51(30.00)$ \\
\hline WHtR & 0.60 & 0.59 & 0.08 & 0.53 & $170(100)$ \\
\hline \multicolumn{6}{|l|}{ Morbidities } \\
\hline None $*$ & & & & & $49(28.82)$ \\
\hline Hypertension * & & & & & $103(58.52)$ \\
\hline Diabetes * & & & & & $26(14.77)$ \\
\hline Overweight $^{\S}$ & & & & & $60(34.10)$ \\
\hline Obesity ${ }^{\S}$ & & & & & $51(28.98)$ \\
\hline \multicolumn{6}{|l|}{ Lifestyle } \\
\hline User of medications & & & & & $125(71.02)$ \\
\hline User of anti-inflammatories & & & & & $15(8.52)$ \\
\hline \multicolumn{6}{|l|}{ Biochemical data } \\
\hline C-reactive protein $(\mathrm{PCR})(\mathrm{mg} / \mathrm{dL})$ & 2.83 & 1.60 & 3.20 & 19.19 & \\
\hline
\end{tabular}

With regard to CRP, most patient values were within the reference range values. Based on the Spearman's test, due to the non-normality of the WHtR, CRP, alcohol consumption and age variables, the correlation between WHtR and CRP was significant ( $p=0.0379, \mathrm{r}=0.16)$, and it could be inferred that as WHtR increases, CRP also increases (Table 2).

Table 2. Correlation between WHtR, CRP, alcohol consumption and the participants' ages.

\begin{tabular}{lcc}
\hline Correlation & $\mathbf{r}$ & $\boldsymbol{p}$-value \\
\hline $\mathrm{WHtR}-\mathrm{CRP}$ & 0.16 & $0.0379^{*}$ \\
\hline $\mathrm{WHtR}-$ Age & 0.12 & 0.1152 \\
\hline $\mathrm{CRP}-$ Age & -0.05 & 0.5126 \\
\hline
\end{tabular}

Notes: Spearman's correlation analysis; $* p<0.05$.

When examining whether obesity, hypertension, diabetes, dyslipidemia and cardiovascular diseases (in isolation) were combined with WHtR, the only association was with obesity, with a $p$-value of 0.0019 (data not shown). By linking WHtR and CRP with discrete variables (Wilcoxon test), individuals without comorbidities had lower mean WHtR values compared to individuals with one or more comorbidities $(p=0.0075)$. Moreover, males have had lower WHtR values than females $(p=0.0490)$ (Figure 1).

By investigating the effect of several variables on WHtR in the multiple linear regression model and the subsequent exclusion of non-significant variables, the model of WHtR $=0.5634+0.0415 \times$ morbidities (isolated or combined) was obtained, suggesting that in individuals with one or more of the most prevalent comorbidities found in this study, the average WHtR increased by 0.0415 units $(p=0.0065)$. However, in the second model proposed, no variable was significantly combined with CRP (Figure 2). 
Figure 1. Mean WHtR values between the individuals without morbidities and those with 1 or more morbidities.

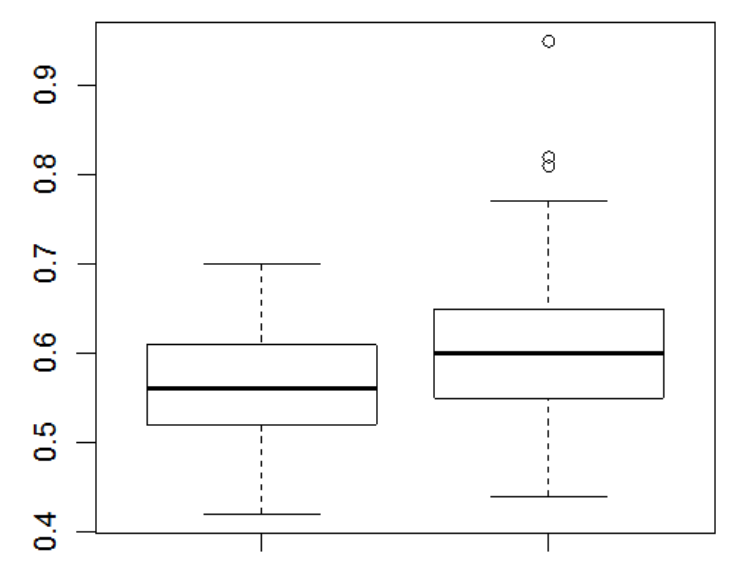

Figure 2. WHtR values for males and females. Wilcoxon test for the comparison of the means; $p<0.05$.

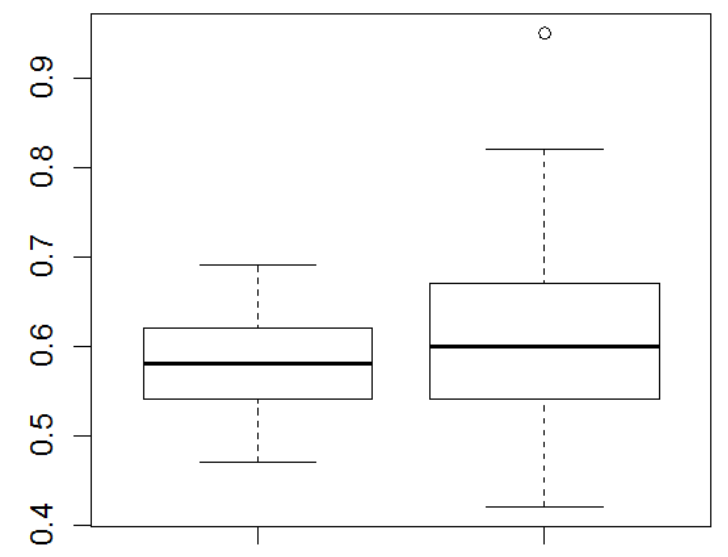

\section{Discussion}

In the present study, we observed associations between WHtR, isolated and combined morbidity and CRP among the elderly. The association between the WHtR values and the occurrence of morbidities analyzed in isolation (i.e., the number of individuals with only one morbidity) and combined (i.e., the number of individuals with one or more of the most prevalent morbidities) in the elderly population of João Pessoa was analyzed based on a multiple regression model, along with the association between CRP values and WHtR.

The association between high WHtR levels and the occurrence of one or more morbidities (combined) of high prevalence, such as hypertension, obesity and diabetes, is an unpublished result. The average WHtR value of individuals without any morbidity was lower than in individuals with at least one morbidity. A literature search revealed that the associations between anthropometric indicators and morbidities were analyzed only in isolation (i.e., in the number of individuals who were carriers of each of the components related to cardiovascular risk factors, such as type-2 diabetes mellitus or metabolic syndrome) [12,30,31].

The high frequency of individuals with high WHtR levels (90\%) in this study reinforces the results obtained from a cohort study in Taiwan involving subjects with an average age of $62.1( \pm 10.9)$ years, 
in which the prevalence of high WHtR $(>0.50)$ was $83.9 \%$ [31]. Because abdominal obesity plays a key role in mortality due to cardiometabolic diseases, this anthropometric parameter is of great importance as a screening tool in the elderly [12].

With respect to the influence of gender, it has been found that males have lower average WHtR values than females. These data are consistent with the findings of Jayawardana et al. [32] who observed that in a sample of 4,485 adults from South Asia over the age of 18 years, men had WHtR values that were significantly lower than those of women. This heterogeneity in the abdominal obesity distribution between genders is also consistent with the results described by Veloso and Silva [33] who found that the prevalence of abdominal obesity among adult women (verified by waist circumference) twice that of men. It is suggested that higher prevalence in women can be attributed to the greater amount of body fat commonly reported for females, pregnancy, hormonal differences and menopause [34]. Regarding these gender differences in the elderly, no justifications were found in the literature, and while it is possible that hormonal differences are an important factor, other factors may also affect fat distribution, including whether adult lifestyles are maintained or change with advancing age.

Regarding the association between WHtR and CRP values in this study, Palacios et al. [35] investigated the relationship between adiposity values and cardiometabolic risk factors in adults (21-79 years) living in Puerto Rico and also observed a relationship between these variables, indicating that CRP increases as WHtR increases. Notably, the CRP values observed in this study are mostly within the reference ranges, a fact that may have contributed to the findings relating to the low $p$-value.

The anthropometric parameter WHtR appears to be related to the onset of new cases of cardiovascular diseases in elderly individuals living in the rural area of Taiwan with wherein high WHtR levels (>0.50) were reported [30]. Similarly, Jayawardana et al. [32] reported that before the morbidities combined with cardiovascular diseases appear, alterations in the WHtR values had already been observed with the occurrence of diabetes and hypertension when these latter conditions were analyzed in isolation

The relationships found demonstrated in this study reinforce the importance of using this anthropometric indicator as a screening tool because it is related to the most prevalent and most common morbidities analyzed in combination in individuals and not just merely to a certain morbidity in a population, as reported in other studies [10,31].

\section{Conclusions}

We concluded that, further studies should be performed with other populations and in different age groups, and cohort studies should be developed to verify whether the improvement of isolated and combined morbidities accompanied by a reduction in the values that are associated with of this relationship, which would better support the recommendation of using WHtR to screen for the combined morbidities that are most prevalent in a given population. It was considered the limitations of study cross-sectional design and self - reported morbidities. 


\section{Acknowledgments}

The authors wish to thank the research coordinator, Maria José de Carvalho Costa, and her team of teachers, graduate and undergraduate students, and the funding agencies that facilitated the performance of this research (National Research Council (CNPq) and the Ministry of Health and Research Support Foundation of the State of Paraíba (FAPESQ, PB, Brazil), processes number 004/06, 1-003/06, PP-SUS), as well as the research collaborators (Graduate Program in Nutritional Sciences, “Lauro Wanderley” University Hospital, Center for Micronutrient Research/Federal University of Paraíba).

\section{Author Contributions}

Jousianny Patrício da Silva contributed to data management, statistical analysis, data interpretation and manuscript writing. Cassia Surama de Oliveira Silva, Raquel Patrícia Ataíde Lima, Danielle de Carvalho Pereira contributed to data acquisition, data management and data interpretation. Maria da Conceição Rodrigues Gonçalves, Rosália Gouveia Filizola have been involved in drafting the manuscript or revising it critically for important intellectual content. Ronei Marcos de Moraes contributed to the study design and the statistical analysis. Luiza Sonia Rios Asciutti and Malaquias Batista Filho contributed to manuscript writing and have been involved in drafting the manuscript or revising it critically for important intellectual content. Maria José de Carvalho Costa contributed to the study design, statistical analysis data interpretation, manuscript writing, coordinated the data collection and have been involved in drafting the manuscript or revising it critically for important intellectual content. All authors read and approved the final manuscript.

\section{Conflicts of Interest}

The authors declare no conflict of interest.

\section{References}

1. Institute of Municipal Development and State of Paraíba (IDEME). IDEME Presents Study on the Elderly Population of Paraíba between 2000 and 2010. Available online: http://www.paraiba.pb. gov.br/57491/ideme-apresenta-estudo-sobre-a-populacao-idosa-da-paraiba-entre-2000-e2010.html (accessed on 29 October 2013).

2. Kearney, P.; Cronin, H; O’Regan, C.; Kamiya, Y.; Savva, G.; Whelan, B.; Kenny, R. Cohort profile: The Irish longitudinal study on ageing. Int. J. Epidemiol. 2011, 40, 877-884.

3. Demographic Evolution, 1950-2010; Brazilian Institute of Geography and Statistics: Rio de Janeiro, Brazil, 2010.

4. Huerta, J.; Gonzáles, S.; Fernandéz, S.; Patterson, A.; Lasheras, C. Lipid peroxidation, antioxidant status and survival in institucionalised elderly: A five-years longitudinal study. Free Radical Res. 2006, 40, 571-578.

5. Keep Fit Far Life: Meeting the Nutritional Needs of Older Persons; World Health Organization (WHO): Geneva, Switzerland, 2002.

6. Vlassopoulos, A.; Combet, E.; Lean, M.E. Changing distributions of body size and adiposity with age. Int. J. Obesity 2014, 38, 857-864. 
7. Pinho, C.; Diniz, A.; Arruda, I.; Batista Filho, M.; Coelho, P.; Sequeira, L.; Lira, P. Prevalence of abdominal obesity and associated factors among individuals 25 to 59 years of age in Pernambuco State, Brazil. Cad. Saúde. Pública. 2013, 29, 313-324.

8. Deaton, C.; Froelicher, E.; Wuc, L.; Ho, C.; Shishani, K.; Jaarsma, T. The global burden of cardiovascular disease. Eur. J. Cardiovasc. Nurs. 2011, 10, 5-13.

9. Li, W.; Chen, I.; Chang, Y.; Loke, S.; Wang, S.; Hsiao, K. Waist-to-height ratio, waist circumference, and body mass index as indices of cardiometabolic risk among 36.642 Taiwanese adults. Eur. J. Nutr. 2013, 52, 57-65.

10. Tatsumi, Y.; Watanabe, M.; Kokubo, Y.; Nishimura, K.; Higashiyama, A.; Okamura, T.; Okayama, A.; Miyamoto, Y. Effect of age on the association between waist-to-height ratio and incidence of cardiovascular disease: The Suita study. J. Epidemiol. 2013, 23, 351-359.

11. Dong, X.; Liu, Y.; Yang, J.; Sun, Y.; Chen, L. Efficiency of anthropometric indicators of obesity for identifying cardiovascular risk factors in a Chinese population. Postgrad. Med. J. 2011, 87, 251-256.

12. Guasch-Ferré, M.; Bulló, M.; Martínez-González, M.; Corella, D.; Estruch, R.; Covas, M.; Arós, F.; Warnberg, J.; Fiol, M.; Lapetra, J.; Munõz, M.; Serra-Majem, L.; Pinto, X.; Babio, N.; Díaz-López, A.; Salas-Salvado, J. Waist-to-height ratio and cardiovascular risk factors in elderly individuals at high cardiovascular risk. PLoS One 2012, 7, doi:10.1371/journal.pone.0043275.

13. García-Bailo, B.; da Costa, L.; Arora, P.; Karmali, M.; El-Sohemy, A.; Badawi, A. Plasma vitamin D and biomarkers of cardiometabolic disease risk in adult Canadians, 2007-2009. Prev. Chronic Dis. 2013, 10, doi:10.5888/pcd10.120230.

14. Mcdade, T.; Rutherford, J.; Adair, L.; Kuzawa, C. Population differences in associations between C-reactive protein concentration and adiposity: Comparison of young adults in the Philippines and the United States. Amer. J. Clin. Nutr. 2009, 89, 1237-1245.

15. Phillips, C.; Perry, I. Does inflammation determine metabolic health status in obese and nonobese adults? J. Clin. Endocrinol. Metab. 2013, 98, 1-10.

16. Wu, S.; Li, J.; Li, Y.; Jin, C.; Wang, L.; Ruan, C.; Zhu, J.; Wang, N.; Zhang, Z.; Wang, Y.; Wang, J. The distribution and influential factors of serum high sensitivity C-reactive protein in general population. Zhonghua Nei Ke Za Zhi 2010, 49, 1010-1014.

17. Correia, L.; Penalva, R.; Correia, H.; Ladeia, A.; Menezes, M.; Suzart, I.; Moreira, A.; Lima, J.; Galvão, B.; Guimarães, A. Determinants of C-reactive protein in individuals very low socioeconomic status. Arq. Bras. Cardiol. 2010, 94, 216-223.

18. Yang, T.; Chou, Y.C.; Chu, C.H.; Lin, S.H.; Hsieh, P.C.; Hsu, C.H.; Bai, C.H.; You, S.L.; Sun, C.A. Metabolic syndrome and C-reactive protein concentration as independent correlates of chronic kidney disease. Endocr. Res. 2014, 39, 94-98.

19. Heron, M. Deaths: Leading Causes for 2007. National Vital Statistics Reports, 26 August 2011. Available online: http://www.cdc.gov/nchs/data/nvsr/nvsr59/nvsr59_08.pdf (accessed on 11 September 2014).

20. Ogden, C.L.; Margaret, D.; Caroll, M.S.P.H.; Brian, K.K.; Flegal, K.M. Prevalence of Obesity in the United States, 2009-2010, NCHS Data Brief, 2012. Available online: http://www.cdc.gov/ nchs/data/databriefs/db82.pdf (accessed on 9 September 2014). 
21. Calder, P.C.; Ahluwalia, N.; Brouns, F.; Buetler, T.; Clement, K.; Cunningham, K.; Esposito, K.; Jönsson, L.S.; Kolb, H.; Lansink, M.; Marcos, A.; Margioris, A.; Matusheski, N.; Nordmann, H.; O’brien, J.; Pugliese, G.; Rizkalla, S.; Schalkwijk, C.; Tuomilehto, J.; Wärnberg, J.; Watzl, B.; Winklhofer-Roob, B.M. Dietary factors and low-grade inflammation in relation to overweight and obesity. Brit. J. Nutr. 2011, 106, 5-78.

22. R Development Team. R: A Language and Environment for Statistical Computing. R Foundation for Statistical Computing, 2009. Available online: http://www.r-project.org (accessed on 16 April 2010).

23. Luna, R.; Nascimento, C.; Asciutti, L.; Franceschini, S.; Filizola, R.; Diniz, A.; Moraes, R.; Rivera, M.; Gonçalves, M.; Costa, M. Relation between glucose levels, high-sensitivity C-reactive protein (hs-CRP), body mass index (BMI) and serum and dietary retinol in elderly in population-based study. Arch. Gerontol. Geriatr. 2011, 54, 462-468.

24. WHO Consultation on Obesity. Obesity: Preventing and Managing the Global Epidemic; WHO: Geneva, Switzerland, 1997.

25. Browning, L.; Hsieh, S.; Ashwel, M. A systematic review of waist-to-height ratio as a screening tool for the prediction of cardiovascular disease and diabetes: 0.5 could be a suitable global boundary value. Nutr. Res. Rev. 2010, 23, 247-269.

26. Herbeth, B.; Siest, G.; Henny, J. High-sensitivity C-reactive protein (CRP) reference intervals in the elderly. Clin. Chem. Lab. Med. 2001, 39, 1169-1170.

27. Lino, V.; Portela, M.; Camacho, L.; Atie, S.; Lima, M. Assessment of social support and its association to depression, self-perceived health and chronic diseases in elderly individuals residing in an area of poverty and social vulnerability in Rio de Janeiro City, Brazil. PLos One 2013, 8, doi:10.1371/journal.pone.0071712.

28. Navaneethan, S.D.; Kirwan, J.P.; Arrigain, S.; Sehgal, A.; Schold, J. Overweight, obesity and international weight loss in chronic kidney disease: NHANES 1999-2006. Int. J. Obes. 2012, 36, 1585-1590.

29. American College of Sports Medicine. Available online: www.acsm.org/docs/fit-society-page/ 2011summerfspn_behaviorchange.pdf (accessed on 30 November 2012).

30. Kuo, R.J.; Wu, Y.H.; Chen, L.K. Inability of waist-to-height ratio to predict new onset diabetes mellitus among older adults in Taiwan: A five-year observational cohort study. Arch. Gerontol. Geriatr. 2011, 53, 1-4.

31. Xu, Z.; Qi, X.; Dahl, A.; Xu, W. Waist-to-height ratio is the best indicator for undiagnosed Type 2 diabete. Diabet. Med. 2013, 30, 201-207.

32. Jayawardana, R.; Ranasinghe, P.; Sheriff, M.; Matthews, D.; Katulanda, P. Waist to height ratio: A better anthropometric marker of diabetes and cardio-metabolic risks in South Asian adults. Diabetes Res. Clin. Pract. 2013, 99, 292-299.

33. Veloso, H.; Silva, A. Prevalência e fatores associados à obesidade abdominal e ao excesso de peso em adultos maranhenses. Rev. Bras. Epidemiol. 2010, 13, 400-412.

34. Ronsoni, R.; Coutinho, M.; Pereira, M.; Silva, R.; Becker, I.; Sehnen, L., Jr. Prevalence of obesity and its associated factors in the population of Tubarão-SC. Arq. Catarin Med. 2005, 34, 51-57. 
35. Palacios, C.; Pérez, C.; Guzmán, M.; Ortiz, A.; Ayala, A.; Suárez, E. Association between adiposity indices and cardiometabolic risk factors among adults living in Puerto Rico. Public Health Nutr. 2011, 14, 1714-1723.

(C) 2014 by the authors; licensee MDPI, Basel, Switzerland. This article is an open access article distributed under the terms and conditions of the Creative Commons Attribution license (http://creativecommons.org/licenses/by/3.0/). 